\title{
Fake news and dental education
}

\author{
Marco Antonio Dias da Silva ${ }^{1,2 *}$ and Anthony Damien Walmsley ${ }^{1}$
}

\section{Key points}

\begin{abstract}
Fake news is used to spread disinformation on many subjects with the aim of distorting the truth. There has been a rise of fake news stories in dentistry such as homemade whitening products and misinformed information on how to strengthen your teeth. Such stories populate YouTube and other social media. Evidence-based dentistry does not provide all the answers, so patients and health professions readily seek out information that confirms their own views on the subject. There are tools available that may be used to verify the accuracy of such information and help to dispel fake news. The ideal way to deal with the influence of fake news is to empower individuals to publish and create an environment of 'real news'.
\end{abstract}

'I heard the news today, oh boy. Four thousand holes in Blackburn, Lancashire...' In 1967, the lyrics of the Lennon/McCartney song were influenced by a news article and the reference to 4,000 holes was then linked to fitting them in the Albert Hall. ${ }^{1}$ Was this an early example of 'fake news'? Roll on to the present and 'fake news' is a term that is used widely so much so that it was named the 2017 word of the year. ${ }^{2}$

Fake news is defined as false stories that masquerade as bona fide news stories. They circulate both on the internet and on social media convincing many unsuspecting readers that they are real. They are typically created to influence political views or portrayed as a joke. ${ }^{2}$ The reporting of an accidental or nonintentional situation that can be corrected is called misinformation. While the act of deliberately producing and spreading material that is wrong in order to intentionally

'University of Birmingham, School of Dentistry, 5 Mill Pool Way, Edgbaston, Birmingham, B5 7EG, UK; ${ }^{2}$ Universidade Federal de Campina Grande, CSTR, Rod. Patos-Teixeira s/n, 58708-110, Brazil

*Correspondence to: Marco Antonio Dias da Silva Email: M.A.DiasdaSilva@bham.ac.uk

Refereed Paper.

Accepted 21 December 2018

DOI:10.1038/s41415-019-0079-z influence people's opinions in a malicious way and/or obscure the truth is considered disinformation. ${ }^{3}$ This is otherwise known as fake news.

The issue is topical, and the European Commission brought together a group of experts to understand better the implications of the fake news problem. In their report, they define disinformation as all forms of false, inaccurate, or misleading information, presented and promoted to cause public harm or for profit. ${ }^{4}$ While the population is beginning to understand how the spread of fake news stories may influence elections, people's habits and opinions throughout the world, the problem is still persistent, and it looks as if it is here to stay. But, how does the proliferation of fake news work?

Internet search engines are forever capturing information with the intent of refining and adjusting their results to an individual's behaviour pattern. Content is also offered depending on its engagement and popularity. The number of times that something has been cited, liked, disliked, tweeted, retweeted or shared, will increase its chance of reaching internet users. This activity may be automated by robots (bots) or humans (trolls) and therefore some news activity will gain undue importance.
Bots are autonomous programmes designed to interact with computer systems without requiring human intervention. It acts as an automatic social media account. Thousands of bots liking, sharing and retweeting a post, will promote messages related to a specific topic, via a hashtag, making it disproportionately popular. While bots are a nuisance, trolls do even greater damage. Trolls represent evil because of their role in middle earth tales and dungeons and dragons' role-playing games. Internet trolls are similar. Trolls unlike bots are not robots, they are individuals driven by passion or money. Trolls will write social posts to push a plan or an idea, which will be amplified by hundreds of thousands of bots.

The destructive effects of fake news on important events, such as national elections, may have the potential to cause considerable real life changes. Facebook has been pressured to remove and block fake accounts and other forms of disinformation spreading on its network. ${ }^{5}$ Also, newsgathering platforms have been used by different agencies to help detect fake news such as the spread of disinformation in national elections, observed in USA (2016), Pakistan (2016) UK (2017), and Mexico in 2018. ${ }^{6,7}$ It may have serious public health consequences especially if it involves a potentially 
contentious issue such as child vaccination. The Wellcome Trust is collaborating with the charity Shift, researching into how parents with young children made decisions on whether or not to vaccinate their children. ${ }^{8,9}$ The main avenue that parents access health information is via social media. Child vaccination is an area where disinformation is rife and is known to influence decisions potentially harming the health of families. Such fake news stories are easy to find, and they will hide behind a badge of authenticity even though the information is factually incorrect.

Is fake news a problem in dentistry? The quick answer is that it is already present and is not a new issue. Before Google, people talked to a health professional to discuss problems. Now everything is online, immediately accessible and can be read in the comfort of your home. Fake news advertising statements often have the tag line 'the home treatment that dentists don't want you to know about.'

Strong financial or ideological interests are quick to influence the more vulnerable individuals within the population. ${ }^{10}$ There has been a rapid growth of dental health 'fads' such as the use of charcoal toothpaste or other seemingly healthy products to improve the strength of teeth. The latter products are often recommended without the use of fluoride, which is wrongly considered a 'poison'. These products are promoted incessantly over a wide range of social media channels, which in turn promotes a sense of authority about them. While there is a lack of poorly scientifically supported information around such items, it this does not stop them from being used. Recently, recognised brands have started to sell charcoal toothpaste adding fluoride to the list of ingredients. Such commercial companies are capitalising on the popularity that began with little or no scientific support. The problem is that someone stands to benefit from the spread of fake news. ${ }^{11}$

In dentistry, universities are no longer seen as the privileged knowledge holders, and there has been a growth in new institutes and foundations that have established their role in the distribution of evidence around the practice of dentistry. Evidence-based dentistry is recognised as the gold standard for providing high quality information about treatments via randomised controlled trials and meta-analysis. This ensures that various clinical treatments are scientifically proven. ${ }^{12}$ However, many of the procedures in dentistry are based on historical practice rather than having undergone rigorous evidencebased research. Practitioners and the public become impatient waiting for procedures to be fully tested and this leads to demand for positive answers. The proliferation of opinion-based statements or presentations aims to influence people with a favourable and often attractive message. This influencing may occur at several levels. For example, bloggers may put forward new ways to whiten teeth. Ordinary online searches for dental content will easily result in the 'discovery' of supposedly newer, faster, better and cheaper treatments. Homemade teeth whitening preparations, miraculous facial treatments and amazing dental implant-related success stories are some of the most commented examples when searching for dentistry. These, fake news items may also carry a quasi-scientific element making the proposed treatments or therapies look more reliable.

\section{Why does fake news have the power to convince people?}

Information is being pushed from one person to the other so fast that most people just briefly check and repass the content received without reflecting on it or verifying its reliability or veracity. Sensationalistic titles and 'information overload' mislead the public and they believe that something that seems reasonable must be correct. Humans are influenced by confirmation bias, as a result fake news stories often confirm people's beliefs, especially if an item has been seen several times previously, and it starts to be more convincing than the evidenced-based truth. ${ }^{13}$

\section{Is fake news the dark side of evidence-based dentistry?}

The problem may be older than most people believe. The European Journal of Oral Implantology published an editorial describing what they call a scientific plague. Within this editorial, Esposito (2017) defines the problem as involving many studies that are fully or partially faked being published in prestigious peer reviewed journals. Such material is often difficult to check and therefore difficult to quantify. ${ }^{14}$ Evidence-based dentistry checklists are available, but they need to adapt to the speed of delivery of fake news. In such turmoil, it is hoped that there will be organisations that are trustworthy and such examples may include the British Dental Association, the General Dental Council and the Royal Colleges. With the persistence of fake news stories, will the public consider the information on their websites or journals to be trustworthy? The list of such organisations can be widened to the BBC, ITV and CNN. How can the general public be sure that such sites are trustworthy when opposing fake news stories start circulating? Patients, students and dental professionals are being affected in one way or another. Dangerous fake news stories are being disseminated rapidly via social media and even trying to discredit reliable sources, such as the Cancer Research UK website. ${ }^{15,16}$

\section{How do we tackle disinformation?}

The European Commission has suggested several avenues including enhancing the transparency of online content. They suggest simple methods to check that the information is from a credible source and is not fake news. ${ }^{4}$

The first way is simple: 'check the source'. Develop a sceptical mind and do not believe the news on first reading or hearing. This may be difficult as fake news stories aim to play on your emotions. A simple trick for spreading fake news is to confirm suspicions or prejudices. It is worth knowing that any health-related content published by unreliable sources is shared more widely than evidenced-based information. ${ }^{17}$

The second way is by continuing to read and carefully checking the content. Do not rely just on the title alone. Fake news may become so familiar that the majority of people share it as if it was an accurate statement. ${ }^{18}$ If you have received an audio or video file about dentistry that is too good to be true, then try to search for more information online. Check the information against other reliable sources ensuring that the content you are reading has a peer reviewed background to it. The statistics show that $40 \%$ of the health content shared on social media is considered to be fake news and $20 \%$ of such stories came from the same source. ${ }^{10}$ For example, a quick way to check if any published photographs in the article have been used elsewhere is to use https://reverse. photos.

The third way is a simple check on the date of the publication. Sometimes old news will be reintroduced as new or recurrent content.

Even if you follow these simple rules, it is still often difficult to spot the problem. Undoing the problem will take time and that means educating both yourself, your students, colleagues and your patients.

If you are involved with undergraduate or postgraduate courses, then encourage your students to spot fake news and discuss these issues with their peers or their patients. By 
discussing the issues around health-related information, it will enable them to become better informed. Such small steps will make a difference. By reaching out to your students, fellow professionals and patients, you have the power to provide information rather than disinformation.

Stay focused. Humans tend to pay more attention to news that reinforces their own ideas. In addition, people will react to the same news in different ways, according to their own beliefs. In our post-truth era, the purportedly fixed and durable concepts are loosening their hold. Predatory scientific journals publish non-peer-reviewed 'scientific' content. Last but not least, even recognised scientific journals publish polarised research, which potentially can be used to spread only one version of the facts. The best way to deal with fake news influence is to empower individuals to publish and create an environment of 'real news'.

\section{Conclusion}

Fake news is a global issue and may require a concerted international effort to discredit it and promote real news. However, it is also up to each of us in our everyday professional life to tackle the problem, as we are the ideal front-line soldiers to take on the fight against fake news dissemination.

\section{Acknowledgements}

This manuscript is part of the C2Learn project that has received funding from the European Union's Horizon 2020 research and innovation programme under the Marie Sklodowska-Curie grant agreement No 748609.

\section{References}

1. Lennon J, McCartney P. A day in a life. Parlophone/ Capitol, 1967.

2. BBC. What is 2017's word of the year? 2017. Available at https://www.bbc.co.uk/news/uk-41838386 (accessed March 2019).

3. Wardle C. Fake news. It's complicated. 2017. Available at https://medium.com/1st-draft/fake-news-itscomplicated-d0f773766c79 (accessed March 2019).

4. European Commission - High level Group on fake news and online disinformation. A multi-dimensional approach to disinformation. 2018, Available at http://ec.europa. eu/newsroom/dae/document.cfm?doc_id=50271 (accessed March 2019).

5. Haynes B. Facebook removes pages of Brazil activist network before elections. Reuters. 2018. Available at https://uk.reuters.com/article/uk-facebook-brazilelection-exclusive/facebook-removes-pages-of-brazilactivist-network-before-elections-idUKKBN1KF1N6 (accessed March 2019)

6. Krzana. Politics \& Elections. 2018. Available at https:// krzana.com/politics/ (accessed March 2019).

7. BBC. Al to help tackle fake news in Mexican election. 2018. Available at https://www.bbc.co.uk/news/ technology-44655770 (accessed March 2019).

8. Hobbs D. Wellcome launches research to investigate fake health news on social media. Third Sector 2018. Available at https://www.thirdsector.co.uk/ wellcome-launches-research-investigate-fake-healthnews-social-media/digital/article/1488400 (accessed March 2019).

9. Brown D. Wellcome Trust: Health Information - Shift. 2018. Available at https://shiftdesign.org/portfolio/ wellcome-trust-health-misinformation/ (accessed March 2019).

10. Waszak P M, Kasprzycka-Waszak W, Kubanek A. The spread of medical fake news in social media - The pilot quantitative study. Health Policy Technol 2018; 7: 115-118.

11. Colgate. Charcoal Toothpaste: What Is It? 2018. Available at https://www.colgate.com/en-us/oral-health/ basics/selecting-dental-products/charcoal-toothpaste-what-is-it- (accessed March 2019).

12. Kishore M, Panat S R, Aggarwal A, Agarwal N, Upadhyay N, Alok A. Evidence based dental care: integrating clinical expertise with systematic research. J Clin Diagn Res 2014; 8: 259-262.

13. Talluri B C, Urai A E, Tsetsos K, Usher M, Donner T H. Confirmation bias through selective overweighting of choice-consistent evidence. Curr Biol 2018; 28: 3128-3135.

14. Esposito M. Editorial: The scientific plague affecting medical and dental research: from fake news to fake studies. Eur J Oral Implantol 2018; 10: 119-120.

15. Forster K. Revealed: How dangerous fake health news conquered Facebook. The Independent, 2017 Available at https://www.independent.co.uk/life-style/ health-and-families/health-news/fake-news-healthfacebook-cruel-damaging-social-media-mike-adamsnatural-health-ranger-conspiracy-a7498201.html (accessed March 2019).

16. Childs 0 . Don't believe the hype -10 persistent cancer myths debunked. Cancer Research UK. 2014 Available at https://scienceblog.cancerresearchuk.org/2014/03/24/ dont-believe-the-hype-10-persistent-cancer-mythsdebunked/ (accessed March 2019).

17. Vosoughi S, Roy D, Aral S. The spread of true and false news online. Science 2018; 359: 1146-1151.

18. Tandoc E C, Lim Z W, Ling R. Defining 'Fake News'. Digit J 2018; 6: 137-153. 